\title{
Comparative performance of two drug interaction screening programmes analysing a cross-sectional prescription dataset of 84,625 psychiatric inpatients
}

\author{
Zorina, Olesya I ; Haueis, Patrick ; Greil, Waldemar ; Grohmann, Renate ; Kullak-Ublick, Gerd A ;
} Russmann, Stefan

\begin{abstract}
BACKGROUND: Clinical decision support software (CDSS) solutions can automatically identify drug interactions and thereby aim to improve drug safety. However, data on the comparative performance of different CDSS to detect and appropriately classify interactions in real-life prescription datasets is limited. OBJECTIVE: The aim of this study was to compare the results from two different CDSS analysing the pharmacotherapy of a large population of psychiatric inpatients for drug interactions. METHODS: We performed mass analyses of cross-sectional patient-level prescriptions from 84,625 psychiatric inpatients using two CDSS - MediQ and ID PHARMA CHECK(®). Interactions with the highest risk ratings and the most frequent ratings were reclassified according to the Zurich Interaction System (ZHIAS), a multidimensional classification that incorporates the OpeRational ClassificAtion of Drug Interactions (ORCA) and served as a reference standard. RESULTS: MediQ reported 6,133 unique interacting combinations responsible for 270,617 alerts affecting 63,454 patients. ID PHARMA CHECK(®) issued 5,400 interactions and 157,489 alerts in 48,302 patients. Only 2,154 unique interactions were identified by both programmes, but overlap increased with higher risk rating. MediQ reported high-risk interactions in $2.5 \%$ of all patients, compared with $5 \%$ according to ID PHARMA CHECK(®). The positive predictive value for unique major alerts to be (provisionally) contraindicated according to ORCA was higher for MediQ (0.63) than for either of the two ID PHARMA CHECK(®) components (0.42 for hospINDEX and 0.30 for ID MACS). MediQ reported more interactions, and ID PHARMA CHECK(®) tended to classify interactions into a higher risk class, but overall both programmes identified a similar number of (provisionally) contraindicated interactions according to ORCA criteria. Both programmes identified arrhythmia as the most frequent specific risk associated with interactions in psychiatric patients. CONCLUSIONS: CDSS can be used for mass-analysis of prescription data and thereby support quality management. However, in clinical practice CDSS impose an overwhelming alert burden on the prescriber, and prediction of clinical relevance remains a major challenge. Only a small subset of yet to be determined alerts appears suitable for automated display in clinical routine.
\end{abstract}

DOI: https://doi.org/10.1007/s40264-013-0027-9

Posted at the Zurich Open Repository and Archive, University of Zurich

ZORA URL: https://doi.org/10.5167/uzh-76756

Journal Article

Accepted Version

Originally published at: 
Zorina, Olesya I; Haueis, Patrick; Greil, Waldemar; Grohmann, Renate; Kullak-Ublick, Gerd A; Russmann, Stefan (2013). Comparative performance of two drug interaction screening programmes analysing a cross-sectional prescription dataset of 84,625 psychiatric inpatients. Drug Safety, 36(4):247-258.

DOI: https://doi.org/10.1007/s40264-013-0027-9 
Title page

\section{Comparative Performance of Two Drug Interaction Screening Programs Analyzing a Cross-sectional Prescription Dataset of \\ 84,625 Psychiatric Inpatients}

Olesya I. Zorina ${ }^{1}$, Patrick Haueis ${ }^{1}$, Waldemar Greil', Renate Grohmann ${ }^{2}$, Gerd A. Kullak-Ublick ${ }^{1,3}$, Stefan Russmann ${ }^{1,3}$

${ }^{1}$ Department of Clinical Pharmacology and Toxicology, University Hospital Zurich, Zurich, Switzerland

${ }^{2}$ Department of Psychiatry, Ludwig-Maximilian University, Munich, Germany ${ }^{3}$ Zurich Center for Integrative Human Physiology (ZIHP), Zurich, Switzerland

Running title: Drug Interactions in Psychiatric Patients Word count: 4,235 


\section{Acknowledgments}

The authors would like to thank Eveline Jaquenoud Sirot, MediQ, Aargau, Switzerland, and ID Berlin GmbH \& CO KGAA, Berlin, Germany / ID Suisse AG, St. Gallen, Switzerland, for their support of mass analyses for interactions using MediQ and ID PHARMA CHECK.

The current study was supported by unrestricted grants to Stefan Russmann from the Swiss Society of Drug Safety in Psychiatry (SGAMSP) and the Hartmann-Müller Foundation for Medical Research, Zurich, Switzerland. Stefan Russmann provided financial compensation to MediQ and ID Berlin for the use of their software and services. The manuscript was made available to MediQ and ID Berlin before submission, but neither MediQ nor ID PHARMA CHECK had influence on the study design, analysis or interpretation of the results. After completion of the presented study Stefan Russmann negotiated research support with ID Berlin for the conduct of future studies using ID PHARMA CHECK, but the current study was not funded by ID Berlin. All authors declare that no conflicts of interest influenced the presented study.

Renate Grohmann is a member of the project management of AMSP. The AMSP Drug Safety Program is organized by non-profit associations in Germany, Austria and Switzerland. Almost all pharmaceutical companies involved in CNS research contribute financial support to the three associations.

Educational and research grants since 1993:

Austrian Companies: Astra Zeneca Österreich $\mathrm{GmbH}$, Boehringer Ingelheim Austria, Bristol Myers Squibb GmbH, CSC Pharmaceuticals GmbH, Eli Lilly GmbH, Germania Pharma $\mathrm{GmbH}$, GlaxoSmithKline Pharma GmbH, Janssen-Cilag Pharma GmbH, Lundbeck GmbH, Novartis Pharma GmbH, Pfizer Med Inform, Wyeth Lederle Pharma GmbH. German Companies: Abbott GmbH \& Co. KG, AstraZeneca GmbH, Aventis Pharma Deutschland GmbH GE-O/R/N, Bayer Vital GmbH \& Co. KG, Boehringer Mannheim GmbH, Bristol-Myers-Squibb, Ciba Geigy GmbH, Desitin Arzneimittel GmbH, Duphar Pharma GmbH \& Co. KG, Eisai GmbH, esparma GmbH Arzneimittel, GlaxoSmithKline Pharma GmbH \& Co. 
KG, Hoffmann-La Roche AG Medical Affairs, Janssen-Cilag GmbH, Janssen Research Foundation, Knoll Deutschland GmbH, Lilly Deutschland GmbH Niederlassung Bad Homburg, Lundbeck GmbH \& Co. KG, Novartis Pharma GmbH, Nordmark Arzneimittel $\mathrm{GmbH}$, Organon $\mathrm{GmbH}$, Otsuka-Pharma Frankfurt, Pfizer GmbH, Pharmacia \& Upjohn GmbH, Promonta Lundbeck Arzneimittel, Rhone-Poulenc Rohrer, Sanofi-Synthelabo GmbH, Sanofi-Aventis Deutschland, Schering AG, SmithKline Beecham Pharma GmbH, Solvay Arzneimittel $\mathrm{GmbH}$, Synthelabo

Arzneimittel GmbH, Dr. Wilmar Schwabe GmbH \& Co., Thiemann Arzneimittel GmbH, Troponwerke GmbH \& Co. KG, Upjohn GmbH, Wander Pharma GmbH, Wyeth-Pharma $\mathrm{GmbH}$

Swiss Companies: AHP (Schweiz) AG, AstraZeneca AG, Bristol-Myers, Squibb AG, Desitin Pharma GmbH, Eli Lilly (Suisse) S.A., Essex Chemie AG, GlaxoSmithKline AG, JanssenCilag AG, Lundbeck (Suisse) AG, Mepha Pharma AG, Organon AG, Pfizer AG, Pharmacia, Sanofi-Aventis (Suisse) S.A., Sanofi-Synthélabo SA, Servier SA, SmithKlineBeecham AG, Solvay Pharma AG, Wyeth AHP (Suisse) AG, Wyeth Pharmaceuticals AG. 


\section{Correspondence}

Stefan Russmann, MD

Department of Clinical Pharmacology and Toxicology

University Hospital Zurich

Rämistrasse 100, 8091 Zurich, Switzerland

phone: +41442552067

fax: $\quad+41442554411$

e-mail: stefan.russmann@usz.ch 
Table of contents

ABSTRACT

INTRODUCTION

SUBJECTS AND METHODS

Data source and study population

Study design and data processing

CDSS for mass analysis of drug interactions

MediQ

ID PHARMA CHECK

ZHIAS reclassification of interactions identified by CDSS

Data analysis

RESULTS

Identification and classification of drug interactions by CDSS

ZHIAS reclassification of interactions

DISCUSSION

CONCLUSIONS

REFERENCES

TABLES 1 - 6

FIGURE 1 (separate file) 
Figure captions

Figure 1: Overlap between unique combinations identified by MediQ and either of the two major ID PHARMA CHECK information sources. 
Key words

Clinical decision support, drug interactions, drug safety, pharmacoepidemiology, pharmacotherapy, psychiatry 


\section{ABSTRACT}

Background: Clinical Decision Support Software (CDSS) solutions can automatically identify drug interactions and thereby aim to improve drug safety. However, data on the comparative performance of different CDSS to detect and appropriately classify interactions in real-life prescription datasets is limited.

Objective: The aim of this study was to compare the results from two different CDSS analyzing the pharmacotherapy of a large population of psychiatric inpatients for drug interactions.

Methods: We performed mass analyses of cross-sectional patient-level prescriptions from 84,625 psychiatric inpatients using two CDSS, MediQ and ID PHARMA CHECK. Interactions with the highest risk ratings and the most frequent ones were reclassified according to the Zurich Interaction System (ZHIAS), a multidimensional classification that incorporates the Operational Classification of Drug Interactions (ORCA) and served as a reference standard.

Results: MediQ reported 6,133 unique interacting combinations responsible for 270,617 alerts affecting 63,454 patients. ID PHARMA CHECK issued 5,400 interactions and 157,489 alerts in 48,302 patients. Only 2,154 unique interactions were identified by both programs, but overlap increased with higher risk rating. MediQ reported high-risk interactions in $2.5 \%$ of all patients, compared to $5 \%$ according to ID PHARMA CHECK. The positive predictive value for unique major alerts to be (provisionally) contraindicated according to ORCA was higher for MediQ (0.63) than for either of the two ID PHARMA CHECK components $(0.42$ for hospINDEX and 0.30 for ID MACS). MediQ reported more interactions, and ID PHARMA CHECK tended to classify interactions into a higher risk class, but overall both programs identified a similar number of (provisionally) contraindicated interactions according to ORCA criteria. Both programs identified arrhythmia as the most frequent specific risk associated with interactions in psychiatric patients.

Conclusions: CDSS can be used for mass-analysis of prescription data and thereby support quality management. However, in clinical practice CDSS impose an overwhelming alert burden on the prescriber, and prediction of clinical relevance remains a major challenge. Only 
a small subset of yet to be determined alerts appears suitable for automated display in clinical routine. 


\section{INTRODUCTION}

For the prevention of adverse drug reactions (ADR) and their associated morbidity, mortality and costs, drug interactions are a target of particular interest.[1-3] Although only a variable fraction of $A D R$ is related to interactions, most clinically relevant interactions are known and should therefore be avoidable given sufficient awareness at the time of drug prescription.[4, 5] Consequently, a number of clinical decision support software (CDSS) systems that are able to identify concomitantly prescribed interacting drugs and alert the prescriber were developed in recent years.

Such CDSS are promoted as valuable tools to achieve safer prescribing, but they are also subject to important limitations that undermine their acceptance and efficacy in clinical practice.[6-9] Typically, their design focuses on high sensitivity to detect interacting drugs.[1013] However, the unavoidable trade-off is that highly sensitive CDSS based on comprehensive interaction databases impose an overwhelming alert burden on the prescribing physician. This may lead to "alert fatigue", meaning that CDSS-triggered alerts are indiscriminately given little attention or even completely disregarded.[5, 14-17] Therefore, the classification and subsequent selection of drug interactions according to their clinical relevance and management implications is a major challenge for CDSS. Furthermore, available CDSS show major differences in their system architecture, underlying knowledge databases and classification systems, and only few studies evaluated and compared different CDSS using real-life patient data.[13, 18-20] Therefore, two aspects of CDSS deserve particular attention: first, the development of classifications that focus on clinical relevance and management implications of drug interactions; second, the development of methods that allow an objective comparison of the performance of different CDSS using real-life data.

In order to address these issues, we recently developed an extended multidimensional operational classification system, the Zurich Interaction System (ZHIAS). It builds on the widely recognized OpeRational ClassificAtion (ORCA) that focuses on clinical management and identification of interactions that require medical interventions or monitoring.[19, 21] ZHIAS extends ORCA by another three dimensions that contain information on mechanisms 
of interaction, management options and expected adverse outcomes in the format of dichotomous variable. ZHIAS also specifically considers the need to include information on individual patients into alert algorithms. ZHIAS was successfully applied in studies that evaluated interactions identified by CDSS,[22-24] and in a small pilot study where we used ZHIAS also as a "silver standard" for the comparison of different CDSS.[25]

Besides improving the specificity of CDSS through studies that use real-life patient data for an evaluation of their performance, such studies also allow an analysis of local safety problems and may therefore aid in the customized development of preventive measures according to specific local needs. The frequency of critical medication errors varies between different medical specialties and settings, and within that context psychiatric patients are a population of special interest.[26] Many new psychopharmacologic drugs have been introduced in recent years, and although some may have improved safety profiles, previous studies reported that drugs acting on the central nervous system are among those most frequently implicated in ADR.[1, 4] Ageing of the psychiatric population and associated polypharmacy may also contribute to higher incidence of critical drug interactions.[26, 27] Only few studies specifically addressed medication safety in psychiatry and the role of CDSS in improving it.[26, 28] In a previous study, we therefore evaluated the frequency and clinical relevance of drug interactions in a large population of psychiatric inpatients based on the CDSS MediQ.[24] The current study extends our previous work through the use of another CDSS in order to evaluate and compare for the first time the identification and grading of drug interactions by two CDSS in a large real-life prescription dataset.

\section{SUBJECTS AND METHODS}

\section{Data source and study population}

AMSP ("Arzneimittelsicherheit in der Psychiatrie” = Drug Safety in Psychiatry) is an ongoing international multicenter drug safety program that has been collecting data on 
pharmacotherapy and ADR from psychiatric hospitals in a naturalistic setting since 1993. Its methods have been described in detail elsewhere.[29, 30] Briefly, AMSP collects drug prescriptions and adverse events from more than 80 hospitals in Germany, Switzerland, Austria, and for some time Belgium and Hungary. All participating hospitals survey psychiatric inpatients on two reference days per year. The drugs administered on these days are recorded along with the patients' age, gender and leading psychiatric diagnoses. For the current study we used the cross-sectional prescription data from patients surveyed between 1994 and 2008.

\section{Study design and data processing}

We conducted a retrospective analysis of drug interactions in the anonymized AMSP prescription dataset using the CDSS MediQ and ID PHARMA CHECK ${ }^{\circledR}$. The ethics committee had approved the study with a waiver of authorization.

Processing and recoding of the raw data for interaction analyses have been described in detail in our previous study.[24] The original AMSP dataset contained cross-sectional data of 88,029 psychiatric inpatients with a total of 334,056 prescriptions. After exclusion of patients with unidentifiable prescriptions and expansion of multi-ingredient preparations into individual constituents, 84,625 patients with 361,112 prescriptions remained suitable for automated mass analysis with ID PHARMA CHECK. For mass analysis with MediQ we also had to exclude substances not comprised in the MediQ database, thus leaving 84,607 patients with 359,207 prescriptions. The most highly graded (“major") and most frequent drug interactions identified by the two CDSS were subsequently reclassified according to ZHIAS. Interactions resulting in decreased efficacy were also identified as such by both CDSS and further evaluated.

\section{CDSS for mass analysis of drug interactions}


MediQ is a CDSS designed as a web-based stand-alone interaction analysis solution. Mass analysis with MediQ has been described in our previous studies.[22-24] Briefly, we developed a customized web-interface that allowed us to perform mass analysis and automated identification of drug interactions with MediQ. MediQ uses a four-level hierarchical severity classification system of interactions (Table 1). All interactions with the MediQ "high danger" grading were defined as "major" in the current study.

\section{ID PHARMA CHECK}

ID PHARMA CHECK ${ }^{\circledR}$ is a CDSS designed for integrated use with computerized physician order entry (CPOE) and clinical information systems. It has been described in our previous pilot study in a small population of neurological inpatients.[25] ID PHARMA CHECK uses several information sources to determine possible drug interactions. Because each source has its own classification system, it can display a multitude of various alerts, where each is assigned an ID PHARMA CHECK three-level color-coded risk grade and an optional free text comment. The underlying information sources are: 1) hospINDEX drug interaction database, which assigns interactions to one of 6 categories including risk assessment and management recommendations. 2) ID MACS $^{\circledR}$ medical semantic network, which comprises two main mechanisms for drug interaction detection: a) a database that contains interactions between certain drug groups and assigns them to one of three risk categories; and b) an algorithm that automatically detects interactions between cytochrome P450 inhibitors or inducers and substrates, as well as QTc-prolonging drugs. Interactions are assigned to one of three colorcoded risk categories, depending on the type of interaction and the number of simultaneously interacting substances. In order to compare the ID PHARMA CHECK output with the one from MediQ, ID PHARMA CHECK warnings were grouped according to their color codes. The classification systems of ID PHARMA CHECK and the definition of "major" interactions for the comparative purposes of this study are presented in Table 1.

\section{ZHIAS reclassification of interactions identified by CDSS}


We selected the following interactions for ZHIAS reclassification: all interactions that were identified by either MediQ or ID PHARMA CHECK and had received the highest rating of the respective programs ("major"), the top 25 most frequent alerts identified by each program, and all interacting drug pairs that were simultaneously identified by MediQ, hospINDEX and each of the two ID MACS components $(n=166)$. Altogether this accounted for 648 unique interacting pairs. In addition, another 819 interactions detected in this patient dataset had previously been reclassified as part of our previous studies, and this information was also available for our analyses.

ZHIAS is a four-dimensional drug interaction classification system that was developed during the conduct of our previous studies.[22-24] ZHIAS is primarily based on the well-established and documented five-level grading according to the Operational Classification of Drug Interactions (ORCA) criteria.[19, 31] Briefly, ORCA's five operational levels are defined as follows: Grade $1=$ "contraindicated combination". The risk associated with the drug interaction always outweighs the benefit. Grade 2 = "provisionally contraindicated". The combination should be avoided unless the interaction is desired or no alternative is available, monitoring may be necessary. Grade 3 = "conditional risk". Monitoring or alternatives should be considered. Grade 4 = "minimal risk". No special action is needed, unless additional risk factors are present. Grade $5=$ "no interaction". ZHIAS's other three major dimensions use dichotomous variables that relate to patient management, interaction mechanisms and expected adverse effects (see also results, Table 4). An expert panel consisting of clinical pharmacologists, pharmacists, neurologists and psychiatrists discussed the ZHIAS classifications of identified interactions until common agreement was achieved. For our assessments we referred to original and secondary literature, including but not limited to Hansten and Horn's Drug Interactions: analysis and management [31], Stockley's Drug Interactions,[32] and the list of QTc-prolonging drugs maintained by the Arizona Center for Education and Research on Therapeutics (AzCERT).[33]

\section{Data analysis}


Data analysis was primarily descriptive with presentation of results in text, tables and figures, and calculation of medians, means and proportions as appropriate. Correlation of drug interaction grading systems was assessed using Spearman's non-parametric rank correlation coefficient. The positive predictive value for a unique major interaction identified in the given population by a CDSS was calculated as the proportion of interactions classified as ORCA level 1 or 2 among all unique major interactions detected by the respective CDSS. Data management and analyses were performed with STATA Version 11.2 for MacOS X (STATA corporation, College Station, TX, USA) and SPSS Version 19 for Windows (SPSS, Inc., Chicago, IL, USA).

\section{RESULTS}

Demographics, medical diagnoses and pharmacotherapy of the study population have been described in detail in our previous study.[24] Median age of the patients was 51 years (range 9-108), nearly 55\% were female, and schizophrenia (34.3\%) and mood (affective) disorders $(30.5 \%)$ were the leading primary diagnoses. Antipsychotics and antidepressants were the most frequently prescribed drug classes, followed by cardiovascular agents and sedatives / anxiolytics. Patients had a mean of 3.9 concomitant drugs (median $=3$ ); $5 \%$ of all patients had concomitant prescriptions for 9 or more substances.

\section{Identification and classification of drug interactions by CDSS}

An overview of the interaction alerts generated by MediQ and ID PHARMA CHECK is presented in Table 2. MediQ generated a total of 270,617 drug interaction warnings that affected 63,454 patients, excluding additional comments. Only 2,305 interactions in 2,156 patients (2.5\%) were classified as "high danger". ID PHARMA CHECK issued fewer alerts, i.e. 157,489 affecting 48,302 patients, but a two-fold higher proportion of patients $(5,842$ interactions in 4,235 patients; 5.0\%) had combinations classified as "red". 
Identification of unique interacting drug pairs in the study population and their overlap between MediQ and ID PHARMA CHECK are presented in Figure 1. Altogether both CDSS issued alerts relating to 9,379 unique interacting drug combinations. MediQ identified 6,133 and ID PHARMA CHECK 5,400 unique interactions. Only 2,154 (23.0\%) of those were identified by both programs. Among the 5,400 unique combinations identified by ID PHARMA CHECK, quantitative contributions from its underlying sources HospINDEX $(3,310$ combinations) and ID MACS (3,169 combinations) were similar and showed only a moderate overlap $(1,079 ; 20.0 \%)$. Further analysis of the 3,169 interactions contributed by ID MACS showed that its database component had identified 1,370 unique interacting pairs, of which 370 overlapped with hospINDEX and 342 pairs were labeled "red" (contraindicated). The ID MACS algorithm component, responsible for detection of CYP450-mediated interactions and combinations of QTc-prolonging drugs identified another 2,350 potentially interacting combinations (756 overlapping with other sources within ID PHARMA CHECK): 1,217 were combinations of inhibitors or inducers and substrates of various CYP450 enzymes, 968 of QTc-prolonging drugs, and another 165 involved both of those mechanisms.

Stratification of unique interacting drug pairs reported by hospINDEX and MediQ over the identifying source and severity grades assigned by each source is presented in Table 3 . Looking at "major" interactions, MediQ classified 198 out of 6,133 (3.2\%) interactions as "high danger", and hospINDEX 210 out of $3,310(6.3 \%)$ as "likely to or can cause serious consequences". Overall, we observed only a moderate correlation of severity grading between MediQ and hospINDEX for those 1,559 interactions that were identified by both sources (Spearman's rank correlation coefficient $r=-0.43, p<0.001$; negative $r$ is due to the inverse grading conventions). However, the proportion of interactions missed by either hospINDEX or MediQ steadily decreased with increasing severity grades, i.e. from $94.1 \%$ to $30.1 \%$ for hospINDEX, and from $83.7 \%$ to $25.3 \%$ for MediQ. In other words, the probability that both sources identified an interaction was higher if either program had classified the interaction to a higher severity grade; nevertheless, even for "major" interactions the overlap 
was far from complete, i.e. only 72 interactions received a "major" rating from MediQ and hospINDEX.

\section{ZHIAS reclassification of interactions}

An analysis of all reclassified interactions showed that the ORCA classification, used as the core component of ZHIAS and a "silver standard" in this study, correlated more closely with MediQ danger rating than with hospINDEX rating $(|r|=0.72$ vs. $0.41, p<0.001)$. Correlation between ORCA classification and ID MACS database was even lower $(r=0.163)$. Accordingly, also the positive predictive value for unique major alerts to be (provisionally) contraindicated according to ORCA was higher for MediQ (0.63) than for either of the two ID PHARMA CHECK components (0.42 for hospINDEX and 0.30 for ID MACS). This means that compared to ID PHARMA CHECK a unique "major" risk alert from MediQ was more likely to be contraindicated or provisionally contraindicated according to ORCA.

ZHIAS reclassification of all "major" unique interactions reported by MediQ and ID PHARMA CHECK is presented in Table 4. Also for this subset of "major" alerts only, MediQ rating displayed a closer correlation with ORCA, i.e. we assigned a higher proportion of "major" alerts from MediQ than from ID PHARMA CHECK to ORCA classes 1 or 2 (62.7\% for MediQ vs. $42.4 \%$ for hospINDEX and $29.8 \%$ for ID MACS). The presented additional ZHIAS components provide further information on management, mechanisms and expected possible adverse events of those interactions. In most cases, a therapeutic alternative with a lower risk may be available, and/or intense monitoring may be an acceptable option. Pharmacodynamic mechanisms of interaction were more frequent than pharmacokinetic mechanisms, and sometimes both contributed simultaneously to an interaction. Depending on the identifying source between $38.9 \%$ and $60.2 \%$ of interactions cause increased drugs effects; and MediQ as well as both sources of ID PHARMA CHECK indicate that arrhythmias, mostly related to QTc prolongations, are the single most frequent expected ADR: within the studied population 3,908 patients $(4.6 \%)$ had an interacting prescription with an elevated risk of arrhythmia rated as ORCA $1(n=52)$ or $2(n=3,856)$. 
Among 38 warnings classified as "major" by MediQ, hospINDEX and ID MACS, one combination was "contraindicated" according to ORCA, i.e. amiodarone and domperidone, affecting one patient. Twenty-eight were provisionally contraindicated after reclassification; of those, 15 were combinations of MAO inhibitors with serotonergic agents or carbamazepine and 13 combinations of QTc-prolonging antipsychotics with other QTc-prolonging agents. The remaining 9 combinations had a conditional risk according to ORCA.

Among all drug interactions detected by MediQ and/or ID PHARMA CHECK and subsequently reclassified according to ZHIAS, 58 individual drug pairs were classified as contraindicated (ORCA 1), and 193 as provisionally contraindicated (ORCA 2). Tables 5 and 6 present the top 15 most frequently occurring interactions in the study population for each of those categories, respectively. Contraindicated combinations not identified by ID PHARMA CHECK included those of mefenamic acid with ibuprofen or diclofenac, and that of lithium with rofecoxib. The first is a combination of two non-steroidal anti-inflammatory drugs, i.e. a therapeutic duplication, and was found in 13 patients. The second was found in 8 patients, and rofecoxib has meanwhile been withdrawn from the market due to its unfavorable cardiovascular safety profile. In turn, MediQ did not report the therapeutic duplication of celecoxib with ibuprofen, and the QTc-prolonging combination of fluvoxamine with thioridazone. Regarding provisionally contraindicated combinations not in ID PHARMA CHECK, the most prominent is the concomitant administration of two different benzodiazepines (11 unique pairs, found in 1,315 patients). It is followed by the combination of olanzapine with carbamazepine that was prescribed to 550 patients. Of note, in those two cases, as well as in the most frequent ORCA 1 combination (ginkgo biloba with antithrombotics or aspirin), ORCA classification is not necessarily driven by a high resulting risk, but rather by the consideration that these combinations are unjustified due to a lack of (additional) efficacy. Nevertheless, in the case of benzodiazepines different pharmacokinetic properties may sometimes justify their concomitant administration. 


\section{DISCUSSION}

The current study evaluated the performance of two CDSS using cross-sectional prescription data of psychiatric inpatients. Also previous studies compared drug interactions and their classification between various compendia and CDSS.[10-12, 18, 20, 34-39] However, only few studies used real-life prescription data for this purpose and therefore also considered the prevalence of potentially interacting prescriptions in the target population.[13,25] This approach provides a different and more realistic picture of CDSS performance in clinical practice. Furthermore, the high efficiency of the applied automated mass analyses, first presented in our previous study in the same population and now extended to another CDSS,[24] enables us to conduct such studies in very large populations.

MediQ generated 1.7 times more warnings for the studied population than ID PHARMA CHECK. This may indicate higher sensitivity, but high sensitivity for low-risk interactions also implies excessive alert burden that undermines the acceptance and therefore efficacy of CDSS in clinical practice.[14, 17] ID PHARMA CHECK generated 2.5 times more "major" interaction alerts than MediQ. At first glance this suggests high sensitivity particularly for highrisk interactions. However, MediQ showed better correlation with ORCA severity ranking, and after ZHIAS reclassification the number of identified interactions classified as ORCA 1 or 2 was similar for both programs. In a previous study with a much smaller population we were able to reclassify all identified interactions according to ZHIAS and were therefore able to formally calculate comparative sensitivity and positive predictive value against ZHIAS as a "silver standard".[25] There, MediQ had a higher sensitivity to detect interactions classified as ORCA 1 or 2, but because the number of low-risk alerts was also higher, the positive predictive value with regard to presumably relevant ORCA class 1 or 2 interactions was similar between both programs. In contrast, the current study calculated the positive predictive value for major alerts only, and this was now higher for MediQ. Overall it appears that both programs are able to effectively identify high-risk interactions at the price of a very high alert burden. 
The low overlap of identified interactions between the two programs is remarkable and unexpected, although it concerns mainly low-risk interactions of questionable relevance in clinical practice. In order to reduce the alert burden, one may select display of high-risk interactions only. However, we found only a moderate correlation between different risk classifications. Previous studies that compared different interaction classification systems also reported significant disagreements in the inclusion and severity rating of interactions,[12, $18,20]$ and none of the currently available classifications can be considered as a gold standard. ORCA may be one of the most management-oriented and widely accepted classifications and was therefore used as a "silver standard" in this study being the major component of ZHIAS, but it is also subject to interrater variability. Indeed, there were also some discrepancies with our assessments vs. those e.g. from Hansten and Horn's ORCA classifications.[24, 31] Reasons for disagreements include the weighting of therapeutic alternatives and risks vs. benefits, patient-specific factors that play an important but difficult to standardize role for the risk of a potential interaction in individual patients, and risks due to interactions between more than two interacting drugs, e.g. "triple interactions".

Considering such multiple interactions, ID PHARMA CHECK's ID MACS algorithm aims to reduce number of alerts and better quantify risks through recognition of multiple combinations when more than two concomitant drugs are substrates of the same enzyme or are associated with QTc interval prolongation. Instead of issuing several low danger warnings liable to be ignored, ID PHARMA CHECK produces one high-risk alert that is more likely to catch the prescriber's attention. Indeed, the majority of interactions that received top ratings from MediQ, hospINDEX and ID MACS were combinations of MAO inhibitors with SSRI or other serotonergic agents, and concomitant use of QTc-prolonging antipsychotics with other QTCprolonging agents, and these also frequently occur as triple interactions in our real-life prescription data. The extended classification of interaction mechanisms and expected adverse effects used in ZHIAS has the potential to take the concept of multiple risk factors in individual patients even further through integration with other patient-specific information: for example, a combination with hypotension as a possible side effect might be assigned a higher priority if this symptom is already present in a given patient. 
ID PHARMA CHECK, optimized for integration into clinical information systems (CIS), may also analyze prescription data together with the information about a patient's diagnoses and other clinical information, and therefore direct a prescriber's attention towards symptoms that are a possible ADR resulting from an interaction. This can support the identification of ADR as such. In addition ID PHARMA CHECK issues alerts relating to single substances and duplicate medications. One should note that those extra features of ID PHARMA CHECK are not reflected in our comparative quantitative analyses, but may be of additional benefit if ID PHARMA CHECK is fully integrated into a hospital's clinical information system.

Beyond a comparison of different CDSS, the innovative use of CDSS for mass analyses of real-life pharmacotherapy can also make important contributions to local quality management. Our study demonstrates, that CDSS can efficiently identify the most problematic and most frequently occurring interacting prescriptions in a population. This information can subsequently be used for locally customized preventive measures, and an evaluation of the subsequent impact of interventions on prescribing behavior. For example, both CDSS identified arrhythmias as the single most frequent expected ADR associated with interactions in this population of psychiatric patients. This potentially lethal risk as well as the frequently identified therapeutic duplications should urge clinicians to be vigilant and avoid such combinations if possible or implement monitoring as appropriate.

Finally, we must also consider some limitations of our study. First, we cannot exclude that some interactions remained undetected even by both CDSS, and we were therefore not able to calculate the true sensitivity and specificity of the CDSS regarding their identification of drug interactions. We cannot formally quantify this limitation but only assume that the very large number of drug interactions identified by both programs, many of which were not even mentioned in standard full-size reference textbooks, and the increasing overlap in detection with higher severity, makes it unlikely that we missed a high number of high-risk interactions. Second, the large number of 9,379 identified unique interactions precluded their complete reclassification. It is therefore possible that we missed some interactions that we would have 
classified into a clinically relevant ORCA risk class. However, we reclassified also those interactions with the highest prevalence in the study population and used classifications from previous studies; and our previous smaller studies where we reclassified all interactions identified by CDSS demonstrated that we would miss only a negligible proportion of combinations classified as ORCA 1 or 2 with the approach taken in the current study. [22, 23, 25]

Third, because ID MACS is not designed as a stand-alone source of drug interaction knowledge but rather as a supplement to the information provided by hospINDEX, a direct comparison of drug interaction detection and classification was carried out only between hospINDEX as part of ID PHARMA CHECK and MediQ, or full ID PHARMA CHECK output and MediQ, but not with ID MACS separately. Another reason for this is that the severity rating of some ID MACS alerts considers more than two simultaneously interacting substances, whereas a comparison with MediQ must be limited to an analysis of drug pairs. Finally, one must also keep in mind that the databases of the studied CDSS are constantly updated.

\section{CONCLUSIONS}

MediQ and ID PHARMA CHECK show major differences in their performance regarding identification and grading of interactions, as well as presentation of their results. MediQ reported more interactions, and ID PHARMA CHECK tended to classify interactions into a higher risk class, but overall both programs identified a similar number of interactions classified as high risk according to ORCA criteria. The applicability in clinical routine is limited by an overwhelming alert burden on the prescriber for both programs. Therefore, the prediction of clinical relevance remains a major challenge, which even improved classifications and integration of additional patient-specific information into alert algorithm will not be able to fully resolve. Consequently, prescribers may only accept the use of either system for the identification of drug interactions if those are offered as an on-demand option for screening purposes. Therefore, additional development of small subsets of alerts suitable 
for automated display in clinical routine has recently been proposed, and those can also be co-implemented in CDSS that are integrated into clinical information systems with electronic prescription.[13, 40] Last not least our study also demonstrated that CDSS could also be used for mass-analysis of prescription data and thereby play an important role in comprehensive local drug safety and quality management concepts. 


\section{REFERENCES}

1. Gurwitz J, Field T, Judge J, Rochon P, Harrold L, Cadoret C, et al. The incidence of adverse drug events in two large academic long-term care facilities. The American Journal of Medicine. 2005;118(3):251-8.

2. Classen DC, Pestotnik SL, Evans RS, Lloyd JF, Burke JP. Adverse drug events in hospitalized patients. Excess length of stay, extra costs, and attributable mortality. JAMA. 1997 Jan 22-29;277(4):301-6.

3. Ernst FR, Grizzle AJ. Drug-related morbidity and mortality: updating the cost-of-illness model. J Am Pharm Assoc (Wash). 2001 Mar-Apr;41(2):192-9.

4. Bates DW, Cullen DJ, Laird N, Petersen LA, Small SD, Servi D, et al. Incidence of adverse drug events and potential adverse drug events. Implications for prevention. ADE Prevention Study Group. JAMA. 1995 Jul 5;274(1):29-34.

5. Hansten PD. Drug interaction management. Pharm World Sci. 2003 Jun;25(3):94-7.

6. Kaushal R, Shojania KG, Bates DW. Effects of computerized physician order entry and clinical decision support systems on medication safety: a systematic review. Arch Intern Med. 2003 Jun 23;163(12):1409-16.

7. Garg AX, Adhikari NK, McDonald H, Rosas-Arellano MP, Devereaux PJ, Beyene J, et al. Effects of computerized clinical decision support systems on practitioner performance and patient outcomes: a systematic review. JAMA. 2005 Mar 9;293(10):1223-38.

8. Bergk V, Gasse C, Schnell R, Haefeli WE. Requirements for a successful implementation of drug interaction information systems in general practice: results of a questionnaire survey in Germany. Eur J Clin Pharmacol. 2004;60(8):595-602. 
9. Indermitte J, Erba L, Beutler M, Bruppacher R, Haefeli WE, Hersberger KE. Management of potential drug interactions in community pharmacies: a questionnaire-based survey in Switzerland. Eur J Clin Pharmacol. 2007;63(3):297-305.

10. Hazlet TK, Lee TA, Hansten PD, Horn JR. Performance of community pharmacy drug interaction software. J Am Pharm Assoc (Wash). 2001 Mar-Apr;41(2):200-4.

11. Smith WD. Evaluation of Drug Interaction Software to Identify Alerts for Transplant Medications. Ann Pharmacother. 2004;39(1):45-50.

12. Wang LM, Wong M, Lightwood JM, Cheng CM. Black box warning contraindicated comedications: concordance among three major drug interaction screening programs. Ann Pharmacother. 2010 Jan;44(1):28-34.

13. Fritz D, Ceschi A, Curkovic I, Huber M, Egbring M, Kullak-Ublick GA, et al. Comparative evaluation of three clinical decision support systems: prospective screening for medication errors in 100 medical inpatients. Eur J Clin Pharmacol. 2012 Feb 29 (epub ahead of print).

14. Glassman PA, Simon B, Belperio P, Lanto A. Improving recognition of drug interactions: benefits and barriers to using automated drug alerts. Med Care. 2002 Dec;40(12):116171.

15. Isaac T, Weissman JS, Davis RB, Massagli M, Cyrulik A, Sands DZ, et al. Overrides of medication alerts in ambulatory care. Arch Intern Med. 2009 Feb 9;169(3):305-11.

16. Bates DW. Ten Commandments for Effective Clinical Decision Support: Making the Practice of Evidence-based Medicine a Reality. J Am Med Inform Assoc. 2003;10(6):523-30. 
17. van der Sijs H, Aarts J, Vulto A, Berg M. Overriding of drug safety alerts in computerized physician order entry. J Am Med Inform Assoc. 2006 Mar-Apr;13(2):138-47.

18. Fulda TR, Valuck RJ, Vander Zanden J, Parker S, Byrns PJ, Utilization UPD. Disagreement among drug compendia on inclusion and ratings of drug-drug interactions. Curr Ther Res Clin E. 2000 Aug;61(8):540-8.

19. Hansten PD, Horn JR, Hazlet TK. ORCA: OpeRational ClassificAtion of drug interactions. J Am Pharm Assoc (Wash). 2001 Mar-Apr;41(2):161-5.

20. Vitry Al. Comparative assessment of four drug interaction compendia. Br J Clin Pharmacol. 2007;63(6):709-14.

21. Malone DC, Abarca J, Hansten PD, Grizzle AJ, Armstrong EP, Van Bergen RC, et al. Identification of serious drug-drug interactions: results of the partnership to prevent drugdrug interactions. J Am Pharm Assoc. 2004 Mar-Apr;44(2):142-51.

22. Frolich T, Zorina O, Fontana AO, Kullak-Ublick GA, Vollenweider A, Russmann S. Evaluation of medication safety in the discharge medication of 509 surgical inpatients using electronic prescription support software and an extended operational interaction classification. Eur J Clin Pharmacol. 2011 Dec;67(12):1273-82.

23. Guzek M, Zorina OI, Semmler A, Gonzenbach RR, Huber M, Kullak-Ublick GA, et al. Evaluation of drug interactions and dosing in 484 neurological inpatients using clinical decision support software and an extended operational interaction classification system (Zurich Interaction System). Pharmacoepidemiol Drug Saf. 2011 Sep;20(9):930-8.

24. Haueis P, Greil W, Huber M, Grohmann R, Kullak-Ublick GA, Russmann S. Evaluation of drug interactions in a large sample of psychiatric inpatients: a data interface for mass 
analysis with clinical decision support software. Clin Pharmacol Ther. 2011 Oct;90(4):588-96

25. Zorina OI, Haueis P, Semmler A, Marti I, Gonzenbach RR, Guzek M, et al. Comparative evaluation of the drug interaction screening programs MediQ and ID PHARMA CHECK in neurological inpatients. Pharmacoepidemiol Drug Saf. 2012 Apr 20 (epub ahead of print).

26. Rothschild JM, Mann K, Keohane CA, Williams DH, Foskett C, Rosen SL, et al. Medication safety in a psychiatric hospital. Gen Hosp Psychiatry. 2007 MarApr;29(2):156-62.

27. Mojtabai R, Olfson M. National trends in psychotropic medication polypharmacy in officebased psychiatry. Arch Gen Psychiatry. 2010 Jan;67(1):26-36.

28. Weih M, Bachmeier C, Degirmenci U, Sojer R, Kreil S, Thurauf N, et al. Assessment of Possible Drug-Drug Interactions in Psychopharmacotherapy after Hospital Discharge using an Interactive Database. Fortschr Neurol Psychiatr. 2011 Feb;79(2):92-6.

29. Grohmann R, Engel RR, Ruther E, Hippius H. The AMSP drug safety program: methods and global results. Pharmacopsychiatry. 2004 Mar;37 Suppl 1:S4-11.

30. Engel RR, Grohmann R, Ruther E, Hippius H. Research methods in drug surveillance. Pharmacopsychiatry. 2004 Mar;37 Suppl 1:S12-5.

31. Hansten PD, Horn JR. Drug interactions: analysis and management. St. Louis, MO: Wolters Kluwer Health: Facts \& Comparisons; 2010. 
32. Baxter K, Stockley IH. Stockley's drug interactions : a source book of interactions, their mechanisms, clinical importance, and management. 9th ed. London ; Chicago: Pharmaceutical Press; 2010.

33. Woosley RL. Drugs That Prolong the QT Interval and/or Induce Torsades de Pointes; Available from: http://www.azcert.org

34. Jankel CA, Martin BC. Evaluation of six computerized drug interaction screening programs. Am J Hosp Pharm. 1992 Jun;49(6):1430-5.

35. Barrons R. Evaluation of personal digital assistant software for drug interactions. Am J Health Syst Pharm. 2004 Feb 15;61(4):380-5.

36. Abarca J, Colon LR, Wang VS, Malone DC, Murphy JE, Armstrong EP. Evaluation of the performance of drug-drug interaction screening software in community and hospital pharmacies. J Manag Care Pharm. 2006 Jun;12(5):383-9.

37. Vonbach P, Dubied A, Krähenbühl S, Beer JH. Evaluation of frequently used drug interaction screening programs. Pharmacy World \& Science. 2008;30(4):367-74.

38. Abarca J, Malone DC, Armstrong EP, Grizzle AJ, Hansten PD, Van Bergen RC, et al. Concordance of severity ratings provided in four drug interaction compendia. J Am Pharm Assoc. 2004 Mar-Apr;44(2):136-41.

39. Vonbach $\mathrm{P}$, Dubied A, Krahenbuhl S, Beer JH. Evaluation of frequently used drug interaction screening programs. Pharm World Sci. 2008 Aug;30(4):367-74. 
40. Phansalkar S, Desai AA, Bell D, Yoshida E, Doole J, Czochanski M, et al. High-priority drug-drug interactions for use in electronic health records. J Am Med Inform Assoc. 2012 Apr 26. 


\section{TABLES AND FIGURE LEGENDS}

FIGURE LEGENDS

Figure 1: Overlap between unique combinations identified by MediQ and either of the two major ID PHARMA CHECK information sources.

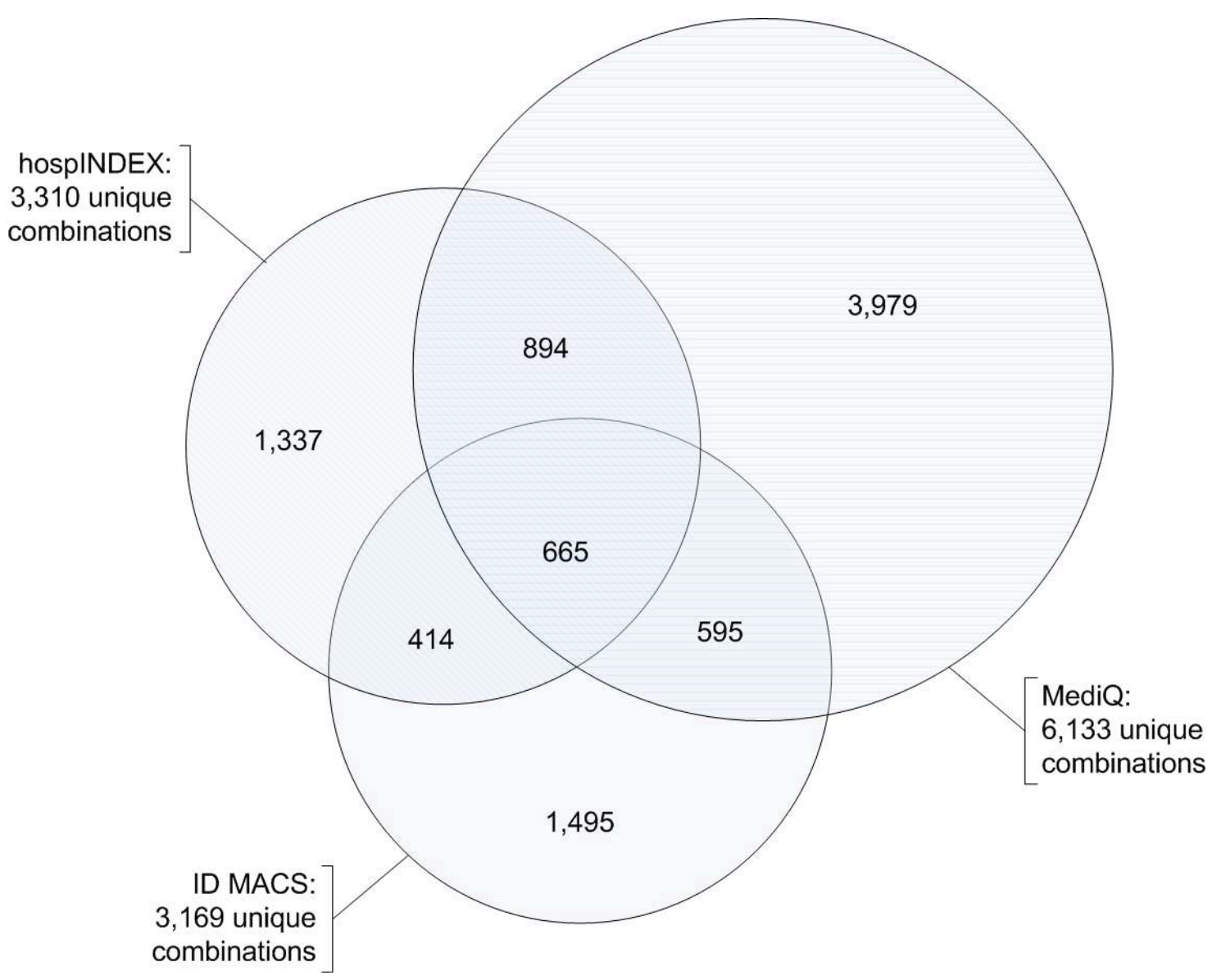




\section{TABLES}

Table 1: Classification of drug interactions by the clinical decision support software (CDSS) solutions MediQ and ID PHARMA CHECK, and our definition of "major" interactions (highlighted in bold script) that were selected for ZHIAS reclassification in the current study.

CDSS Classification of interactions

\begin{tabular}{|c|c|c|}
\hline MediQ & & $\begin{array}{l}3=\text { "strong", high danger of ADR } \\
2=\text { "clinically relevant', average danger of ADR } \\
1=\text { "relevant in exceptional cases", low danger of ADR } \\
0=\text { "no interaction" or favorable combination }\end{array}$ \\
\hline \multirow[t]{3}{*}{$\begin{array}{l}\text { ID PHARMA } \\
\text { CHECK }\end{array}$} & $\begin{array}{l}\text { hospINDEX database } \\
\text { (originally features } 6 \\
\text { risk and management } \\
\text { categories) }\end{array}$ & $\begin{array}{l}\text { Red = "likely to or can cause serious consequences" } \\
\text { Orange = "monitoring or dose adjustment may be required" } \\
\text { Yellow = "monitoring advised" } \\
\text { Blue = "usually no action required" }\end{array}$ \\
\hline & ID MACS database & $\begin{array}{l}\text { Red = "absolute contraindication", "contraindication" } \\
\text { Orange = "relative/conditional contraindication" } \\
\text { Yellow = "use with caution" }\end{array}$ \\
\hline & $\begin{array}{l}\text { ID MACS algorithm for } \\
\text { interactions via } \\
\text { CYP450 enzymes and } \\
\text { QTc prolongations }\end{array}$ & $\begin{array}{l}\text { Red = "substantially increased risk" } \\
\text { Orange = "increased risk" } \\
\text { Yellow = "slightly increased risk" }\end{array}$ \\
\hline
\end{tabular}

$\mathrm{ADR}=$ adverse drug reaction $; \mathrm{CYP} 450=$ cytochrome $\mathrm{P} 450$ 
Table 2: Overview of the output of the drug interaction analyses by MediQ and ID PHARMA CHECK.

\begin{tabular}{llrrrrr}
\hline CDSS & Risk category & Total alerts & Patients affected & \multicolumn{2}{c}{ Alerts per patient } \\
& & $\mathbf{n}$ & $\mathbf{n}$ & $\mathbf{\%}$ & mean & max \\
\hline \multirow{2}{*}{ MediQ } & High to low & & & & & \\
& High to average & 270,617 & 63,454 & 75.0 & 3.20 & 52 \\
& High only & 73,308 & 37,752 & 44.6 & 0.87 & 19 \\
& & 2,305 & 2,156 & 2.5 & 0.03 & 4 \\
\hline \multirow{3}{*}{ ID PHARMA } & Red to yellow & 157,489 & 48,302 & 57.1 & 1.86 & 29 \\
& Red to orange & 86,242 & 38,292 & 45.2 & 1.02 & 20 \\
& Red only & 5,842 & 4,235 & 5.0 & 0.07 & 9 \\
\hline
\end{tabular}


Table 3: Simultaneous stratification of unique interacting drug pairs reported by hospINDEX and MediQ over the identifying source and severity grades assigned by each source.

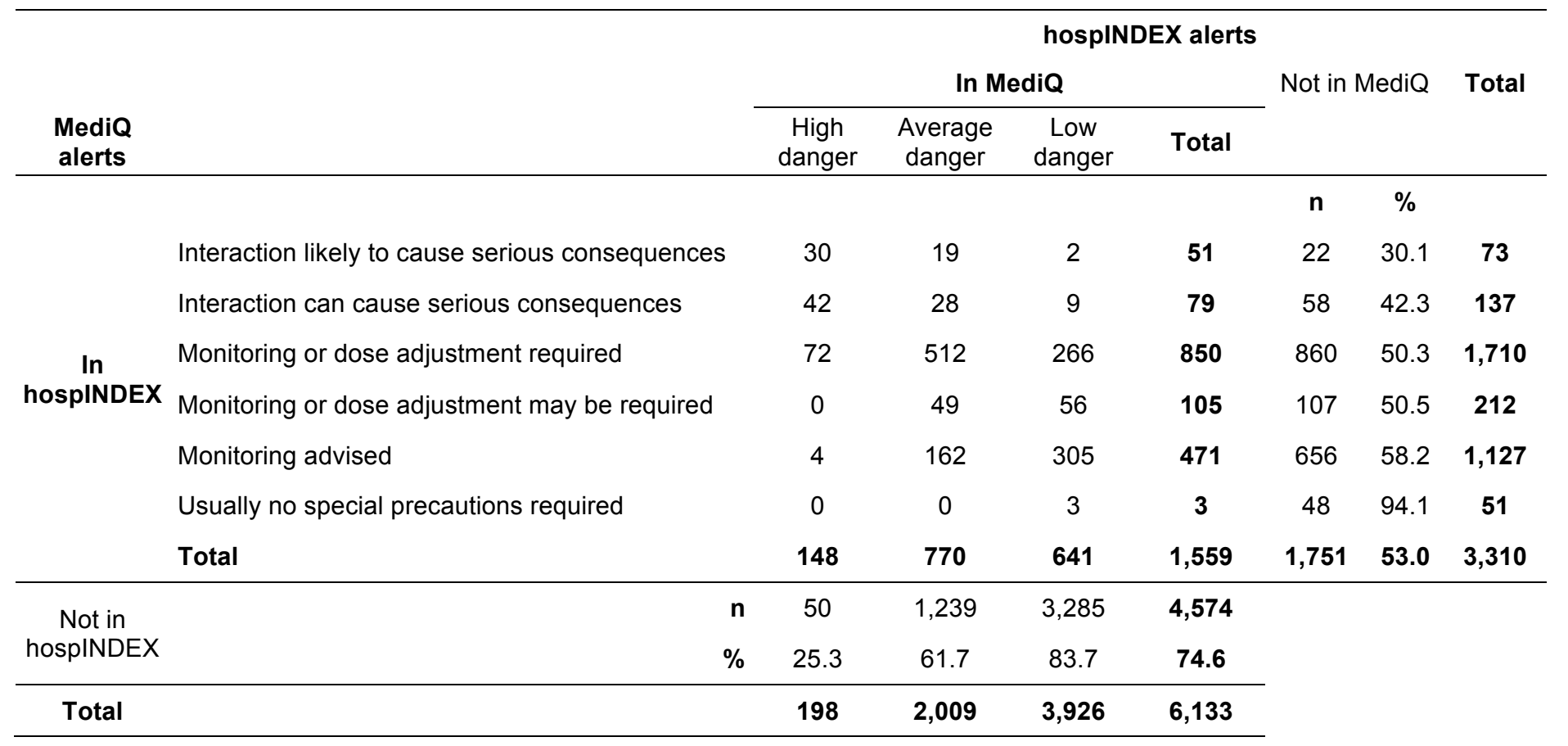


Table 4: Results of the reclassification of all highest-ranked ("major") unique interactions identified by MediQ and each ID PHARMA CHECK source according to ZHIAS.

\begin{tabular}{|c|c|c|c|c|c|c|}
\hline & \multicolumn{2}{|c|}{$\begin{array}{c}\text { MediQ } \\
\text { high danger }\end{array}$} & \multicolumn{2}{|c|}{$\begin{array}{l}\text { hospINDEX } \\
\text { serious consequences } \\
\text { likely / possible }\end{array}$} & \multicolumn{2}{|c|}{$\begin{array}{c}\text { ID MACS } \\
\text { contraindication, } \\
\text { substantially } \\
\text { increased risk } \\
\end{array}$} \\
\hline & $\mathbf{n}$ & $\%$ & $\mathbf{n}$ & $\%$ & $\mathbf{n}$ & $\%$ \\
\hline Total unique combinations & 198 & 100.0 & 210 & 100.0 & 309 & 100.0 \\
\hline \multicolumn{7}{|l|}{ ORCA level } \\
\hline ORCA 1: Contraindicated & 32 & 16.2 & 18 & 8.6 & 12 & 3.9 \\
\hline ORCA 2: Provisionally contraindicated & 92 & 46.5 & 71 & 33.8 & 80 & 25.9 \\
\hline ORCA 3: Conditional risk & 70 & 35.4 & 105 & 50.0 & 173 & 56.0 \\
\hline ORCA 4: Minimal risk & 4 & 2.0 & 16 & 7.6 & 44 & 14.2 \\
\hline \multicolumn{7}{|l|}{ Management } \\
\hline Desired, risk-benefit OK & 38 & 19.2 & 34 & 16.2 & 93 & 30.1 \\
\hline Alternative available & 155 & 78.3 & 136 & 64.8 & 136 & 44.0 \\
\hline Monitoring recommended & 159 & 80.3 & 175 & 83.3 & 262 & 84.8 \\
\hline \multicolumn{7}{|l|}{ Mechanism of interaction ${ }^{1}$} \\
\hline Pharmacokinetic & 87 & 43.9 & 83 & 39.5 & 93 & 30.1 \\
\hline Pharmacodynamic & 149 & 75.3 & 161 & 76.7 & 272 & 88.0 \\
\hline \multicolumn{7}{|c|}{$\begin{array}{l}\text { Expected adverse effects associated with the } \\
\text { interaction }\end{array}$} \\
\hline Drug effect increased & 77 & 38.9 & 113 & 53.8 & 186 & 60.2 \\
\hline Drug effect decreased & 21 & 10.6 & 29 & 13.8 & 18 & 5.8 \\
\hline CNS - sedation, respiratory depression & 17 & 8.6 & 36 & 17.1 & 80 & 25.9 \\
\hline CNS - serotonin syndrome & 42 & 21.2 & 38 & 18.1 & 53 & 17.2 \\
\hline CNS - extrapyramidal syndrome & 8 & 4.0 & 21 & 10.0 & 21 & 7.1 \\
\hline CNS - seizures & 11 & 5.6 & 12 & 5.7 & 5 & 1.6 \\
\hline CNS - other & 38 & 19.2 & 32 & 15.2 & 70 & 22.7 \\
\hline Nephrotoxicity & 1 & 0.5 & 0 & 0.0 & 1 & 0.3 \\
\hline Hepatotoxicity & 1 & 0.5 & 0 & 0.0 & 0 & 0.0 \\
\hline QTc prolongation / Torsade de pointes & 97 & 49.0 & 88 & 41.9 & 159 & 51.5 \\
\hline Arrhythmia & 103 & 52.0 & 113 & 53.8 & 169 & 54.7 \\
\hline Thrombosis & 1 & 0.5 & 9 & 4.3 & 0 & 0.0 \\
\hline Bleeding & 0 & 0.0 & 3 & 1.4 & 2 & 0.6 \\
\hline Hypertension & 17 & 8.6 & 14 & 6.7 & 25 & 8.1 \\
\hline Hypotension & 18 & 9.1 & 38 & 18.1 & 33 & 10.7 \\
\hline Other cardiovascular effects & 1 & 0.5 & 2 & 1.0 & 5 & 1.6 \\
\hline Hyperkalaemia & 9 & 4.5 & 2 & 1.0 & 0 & 0.0 \\
\hline Hypokalaemia, hyponatremia & 5 & 2.5 & 2 & 1.0 & 3 & 1.0 \\
\hline Metabolic and endocrine effects & 3 & 1.5 & 5 & 2.4 & 13 & 4.3 \\
\hline Gastrointestinal toxicity & 1 & 0.5 & 0 & 0.0 & 0 & 0.0 \\
\hline Blood glucose up & 2 & 1.0 & 0 & 0.0 & 0 & 0.0 \\
\hline Blood glucose down & 1 & 0.5 & 0 & 0.0 & 0 & 0.0 \\
\hline
\end{tabular}


Muscle toxicity

$3 \quad 1.5$

2

1.0

2

0.7

Bone marrow toxicity

$3 \quad 1.5$

7

3.4

11

3.6

Other

$10 \quad 5.1$

7

3.4

11

3.6

${ }^{1}$ PK and PD mechanisms can be involved concomitantly; combined total may therefore exceed $100 \%$

${ }^{2}$ Categories are not mutually exclusive and may therefore overlap.

CNS = central nervous system; ORCA = Operational Classification of Drug Interactions 
TABLE 5: 15 most frequent ORCA level 1 (contraindicated) combinations.

\begin{tabular}{|c|c|c|c|c|c|c|}
\hline \multirow[b]{2}{*}{ Drug combination } & \multicolumn{2}{|c|}{$\begin{array}{c}\text { Frequency in } \\
84,625 \text { patients }\end{array}$} & \multicolumn{3}{|c|}{ Danger rating } & \multirow{2}{*}{$\begin{array}{l}\text { Expected } \\
\text { adverse effects }\end{array}$} \\
\hline & $\mathbf{n}$ & $\%$ & MediQ & $\begin{array}{l}\text { hosp- } \\
\text { INDEX }\end{array}$ & $\begin{array}{c}\text { ID } \\
\text { MACS }\end{array}$ & \\
\hline $\begin{array}{l}\text { Ginkgo biloba and } \\
\text { antithrombotics or aspirin }\end{array}$ & 102 & 0.12 & Average & $\begin{array}{l}\text { Monitoring / } \\
\text { DA required }\end{array}$ & - & Bleeding \\
\hline $\begin{array}{l}\text { Cisapride - tricyclic } \\
\text { antidepressants }\end{array}$ & 17 & 0.02 & High & - & * & QTc prolongation \\
\hline $\begin{array}{l}\text { Mefenamic acid - } \\
\text { ibuprofen, diclofenac }\end{array}$ & 13 & 0.02 & Average & - & - & Gl bleeding \\
\hline Celecoxib - ibuprofen & 9 & 0.01 & - & - & Caution & GI bleeding \\
\hline Rofecoxib - lithium & 8 & 0.01 & High & - & - & Lithium intoxication \\
\hline Amiodarone - digoxin & 7 & 0.01 & High & $\begin{array}{l}\text { Monitoring / } \\
\text { DA required }\end{array}$ & - & $\begin{array}{l}\text { Arrhythmia, digoxin } \\
\text { toxicity }\end{array}$ \\
\hline $\begin{array}{l}\text { Carbamazepine - } \\
\text { clarithromycin }\end{array}$ & 7 & 0.01 & High & $\begin{array}{l}\text { May cause } \\
\text { SC }\end{array}$ & * & $\begin{array}{l}\text { Carbamazepine } \\
\text { toxicity }\end{array}$ \\
\hline $\begin{array}{l}\text { Carbamazepine - } \\
\text { midazolam }\end{array}$ & 7 & 0.01 & High & $\begin{array}{l}\text { Monitoring / } \\
\text { DA required }\end{array}$ & * & $\begin{array}{l}\text { Loss of midazolam } \\
\text { efficacy }\end{array}$ \\
\hline $\begin{array}{l}\text { Fluvoxamine - } \\
\text { thioridazine }\end{array}$ & 7 & 0.01 & - & $\begin{array}{l}\text { Likely to } \\
\text { cause SC }\end{array}$ & $A C^{1}$ & QTc prolongation \\
\hline $\begin{array}{l}\text { Atazanavir - } \\
\text { pantoprazole }\end{array}$ & 6 & 0.01 & Average & $\begin{array}{l}\text { Likely to } \\
\text { cause SC }\end{array}$ & - & $\begin{array}{l}\text { Loss of antiviral } \\
\text { activity }\end{array}$ \\
\hline $\begin{array}{l}\text { Fenoterol, salmeterol - } \\
\text { nonselective } \beta \text {-blockers }\end{array}$ & 6 & 0.01 & High & $\begin{array}{l}\text { Monitoring } \\
\text { /DA required }\end{array}$ & - & Bronchospasm \\
\hline Fentanyl - tramadol & 5 & 0.01 & Average & - & - & $\begin{array}{l}\text { Serotonin } \\
\text { syndrome, seizures }\end{array}$ \\
\hline $\begin{array}{l}\text { Haloperidol - } \\
\text { erythromycin }\end{array}$ & 5 & 0.01 & High & $\begin{array}{l}\text { Monitoring / } \\
\text { DA required }\end{array}$ & $\mathrm{RC}^{1}$ & $\begin{array}{l}\text { EPS, QTc } \\
\text { prolongation }\end{array}$ \\
\hline Levodopa - tiapride & 5 & 0.01 & High & $\begin{array}{l}\text { May cause } \\
\text { SC }\end{array}$ & - & $\begin{array}{l}\text { Loss of levodopa } \\
\text { efficacy }\end{array}$ \\
\hline $\begin{array}{l}\text { Sibutramine - SSRI, } \\
\text { other serotonergic drugs }\end{array}$ & 5 & 0.01 & Varies & $\begin{array}{l}\text { Likely to } \\
\text { cause SC }\end{array}$ & - & Serotonin syndrome \\
\hline
\end{tabular}

${ }^{1}$ combination was also automatically flagged as an interaction between CYP inducer/inhibitor and substrate or a concomitant administration of two QTc-prolonging substances.

$\mathrm{AC}=$ absolute contraindication; $\mathrm{DA}=$ dose adjustment; $\mathrm{EPS}=$ extrapyramidal symptoms; $\mathrm{GI}=$ gastrointestinal; ORCA = Operational Classification of Drug Interactions; $\mathrm{RC}=$ relative contraindication; $\mathrm{SC}=$ serious consequences; SSRI = selective serotonin reuptake inhibitor 
TABLE 6: 15 most frequent ORCA level 2 (provisionally contraindicated) combinations.

\begin{tabular}{|c|c|c|c|c|c|c|}
\hline \multirow[b]{2}{*}{ Drug combination } & \multicolumn{2}{|c|}{$\begin{array}{l}\text { Frequency in } \\
84,625 \text { patients }\end{array}$} & \multicolumn{3}{|c|}{ Danger rating } & \multirow{2}{*}{$\begin{array}{l}\text { Expected } \\
\text { adverse effects }\end{array}$} \\
\hline & $\mathbf{n}$ & $\%$ & MediQ & $\begin{array}{l}\text { hosp- } \\
\text { INDEX }\end{array}$ & $\begin{array}{c}\text { ID } \\
\text { MACS }\end{array}$ & \\
\hline $\begin{array}{l}\text { Any two } \\
\text { benzodiazepines }\end{array}$ & 1,315 & 1.55 & Average & - & - & Sedation \\
\hline Haloperidol - clozapine & 822 & 0.97 & Average & - & $\mathrm{RC}^{1}$ & $\begin{array}{l}\text { QTc prolongation, } \\
\text { sedation }\end{array}$ \\
\hline Haloperidol - olanzapine & 687 & 0.81 & Average & - & $\mathrm{RC}^{1}$ & $\begin{array}{l}\text { QTc prolongation, } \\
\text { metabolic, CNS }\end{array}$ \\
\hline $\begin{array}{l}\text { Haloperidol - } \\
\text { carbamazepine }\end{array}$ & 650 & 0.77 & Average & $\begin{array}{l}\text { Monitoring } \\
\text { advised }\end{array}$ & 1 & $\begin{array}{l}\text { Loss of haloperidol } \\
\text { efficacy }\end{array}$ \\
\hline $\begin{array}{l}\text { Haloperidol - } \\
\text { levomepromazine }\end{array}$ & 624 & 0.74 & Average & - & Caution & $\begin{array}{l}\text { EPS, QTc } \\
\text { prolongation }\end{array}$ \\
\hline $\begin{array}{l}\text { Carbamazepine - } \\
\text { olanzapine }\end{array}$ & 550 & 0.65 & Average & - & - & $\begin{array}{l}\text { Loss of olanzapine } \\
\text { efficacy, metabolic }\end{array}$ \\
\hline $\begin{array}{l}\text { Carbamazepine - } \\
\text { risperidone }\end{array}$ & 500 & 0.59 & Average & $\begin{array}{l}\text { Monitoring } \\
\text { advised }\end{array}$ & - & $\begin{array}{l}\text { Loss of risperidone } \\
\text { efficacy, other CNS }\end{array}$ \\
\hline Clozapine - fluvoxamine & 402 & 0.48 & High & $\begin{array}{l}\text { Monitoring / } \\
\text { DA required }\end{array}$ & 1 & $\begin{array}{l}\text { Bone marrow } \\
\text { toxicity }\end{array}$ \\
\hline $\begin{array}{l}\text { Haloperidol - tricyclic } \\
\text { antidepressants }\end{array}$ & 232 & 0.27 & Average & $\begin{array}{l}\text { Monitoring / } \\
\text { DA required }\end{array}$ & $\mathrm{RC}^{1}$ & $\begin{array}{l}\text { QTc prolongation, } \\
\text { seizures }\end{array}$ \\
\hline $\begin{array}{l}\text { MAO inhibitors - tricyclic } \\
\text { antidepressants }\end{array}$ & 212 & 0.25 & $\mathrm{High}^{2}$ & $\begin{array}{l}\text { Monitoring / } \\
\text { DA required }\end{array}$ & $A C$ & Serotonin syndrome \\
\hline $\begin{array}{l}\text { Lithium - } \\
\text { hydrochlorothiazide }\end{array}$ & 190 & 0.22 & High & $\begin{array}{l}\text { Monitoring / } \\
\text { DA required }\end{array}$ & - & Lithium intoxication \\
\hline $\begin{array}{l}\text { Carbamazepine - } \\
\text { clozapine }\end{array}$ & 183 & 0.22 & Average & $\begin{array}{l}\text { Likely to } \\
\text { cause SC }\end{array}$ & $A C^{1}$ & Agranulocytosis \\
\hline Clozapine - olanzapine & 177 & 0.21 & High & - & 1 & $\begin{array}{l}\text { QTc prolongation, } \\
\text { metabolic }\end{array}$ \\
\hline Clozapine - quetiapine & 168 & 0.20 & Average & - & 1 & $\begin{array}{l}\text { QTc, bone marrow } \\
\text { toxicity, } \\
\text { hypotension, } \\
\text { sedation }\end{array}$ \\
\hline
\end{tabular}

\footnotetext{
${ }^{1}$ Combination was also automatically flagged as an interaction between CYP inducer/inhibitor and substrate or a concomitant administration of two QTc-prolonging substances.

${ }^{2}$ Some combinations were missing from MediQ

$\mathrm{AC}=$ absolute contraindication; $\mathrm{CNS}=$ central nervous system; $\mathrm{DA}=$ dose adjustment; $\mathrm{EPS}=$ extrapyramidal symptoms; $\mathrm{GI}=$ gastrointestinal; $\mathrm{MAO}=$ monoamine oxidase; $\mathrm{ORCA}=$ Operational Classification of Drug Interactions; $\mathrm{RC}=$ relative contraindication; $\mathrm{SC}=$ serious consequences; $\mathrm{SSRI}=$ selective serotonin reuptake inhibitor
} 